\title{
Relationship between Organizational Skills of Time Management and Job Stress among Schools Principals of Zahedan City
}

\author{
Alireza Heidarzadegan (Corresponding author) \\ College of Education and Psychology, Sistan \& Baluchestan University \\ P.O box $98155-773$ Zahedan, Iran
}

Tel: 98-915-543-0547Ｅ-mail: heidarzadegan@edpsy.usb.ac.ir

\begin{abstract}
Sima Nabizadeh Sarabandi
Medical School of Zahedan
\end{abstract}

Tel: 98-915-349-3488Ｅ-mail: nabizadeh41@yahoo.com

\author{
Mahbobe Shamsedini \\ M.A in Educational Administration \\ Tel: 98-913-844-8522Ｅ-mail: shamsedini@yahoo.com
}

Received: July 2, 2012 Accepted: December 31, 2012 Published: February 1, 2013

doi:10.5296/jse.v3i1.2032 URL: http://dx.doi.org/10.5296/jse.v3i1.2032

\begin{abstract}
Purpose: The purpose of this study was to ascertain the Relationship Between Organizational Skills of Time Management (OSTM) and Job Stress (JS) among Schools Principals of Zahedan City in Sistan and Baluchestan province in Iran country.so we want to examine which of the subscales of Organizational Skills of Time Management can better predict job stress of administrations. Method: Population of this research contains all managers (principals), assistants and responsible experts of education department, educational districts 1 and 2, at Zahedan city in Iran country. Since, the population was too small, trend of sampling was not conducted and the whole population was considered. Indeed 67 principals participated in this research and response to questionnaires. For collecting data two questionnaires of time management and occupational stress were used. Findings: Results of
\end{abstract}


Pearson correlation coefficient indicated that there was a significant negative correlation between time management organizational skills and job stress. The results of stepwise regression showed that the scores of management of meetings had a significant negative relationship with job stress and it was a negative predictor for job stress, also operational stress was a negative predictor for job stress. The results of stepwise regression postulated that management of meetings and operational planning were the unique predictors for job stress. In the first step, planning variable explained $14 \%$ of the variance in job stress and in the second step when operational planning was entered into the regression equation explained $23 \%$ of the variance in job stress. Conclusion: the findings In this research postulated that key element in our successful life is time, especially in education organization. As Frost (1992) believes that time, everywhere is a factor of pressure and Time management is the number one tool for managing stress.

Keywords: Organizational Skills, Time Management, Job Stress, Schools Principals 


\section{Introduction}

Pace of evaluation and change in the whole prevailing conditions on the present world has challenged every one seriously and critically to make quick decision and take immediate action. Logic conception of speed in decision-making and action taking means not to miss any opportunity and not to waste any capital which cannot be revived and re-created at any cost (Mashayekhi, 2003). Rise of competition in the world of economy and increase in demands for providing products and services during past two decades have caused time dimension of work to become more important. Due to these changes, the pace of life has been quicker and people have been forced to do their works quicker. That is why, the need for time management is felt more than before (Orlikowesky, 2002). According to Mackenzie (1993) "Time is a flowing capital that has got free from existing traps in the framework of positive guidance, and has guided us to the peaks of perfection. Chung (1989) suggests that: "now a day, the world is saturated with valuable things. House, land, properties and assets..., among them, Time is the most valuable. Waste of time is more regretful than loss of money, because you are always capable of earning money, but time, never come back." Time management is a series of principles, activities, skills, tools, and systems that work together to help you to acquire more value of time with the aim of optimizing the quality of your life (Green and Skinner, 2005). Brigitte (2007) defines time management as follows: "Behaviors, the aim of which is access to time use, effectively during implementation of activities on the direction of goal."'This definition clarifies that use of time is not goal by itself and cannot be followed separately. Focus on activities which are on the direction of goal, carried out in a way that indicates effective use of time. These behaviors include:(1) Time assessment behaviors, the goal of which involves awareness of here, know (present) past and future; as well as self awareness of personal time use that helps us to accept those duties and responsibilities that are adopted with individual capacities limitations. (2) Planning behaviors, such as setting goals, planning tasks, prioritizing, making to-do lists, groups task which goal at an effective use of time. (3) Monitoring behaviors, which aim at observing one's use of time while performing activities, generating a feedback loop that allows a limit to the influence of interruptions by others. Time management can be considered as an approach to survey and control the time (Nonise, 2005). Time management possesses a positive impact on workers' psychological health and declines their stress and psychologically pressures, that caused by working. Planning and surveying the time result are more reasonable consequences and the functions are performed more effectively then maximum intellectual exploitation is achieved (Arnold, 2004). Frost (1992) believes that time, everywhere is a factor of pressure. This valuable resource is potentially associated with job stress. Stress is a dynamic situation where a placed for meeting what he/she hopes, opportunity, demand or desire, the outcome of which is uncertain but important (Robbins, 2009). Job pressure is an adoptable reaction to external circumstance, resulting in organizations members' physical, mental and behavioral disorders (Luthans, 2002). According to the definition provided by National Institution for job health and immunity "job stress takes place when there is no consistency between individuals' needs, and his/her capability, capacities and wishes (Kendall, 2003). As a psychological state, job stress occurs when a person's job needs are beyond their capabilities (Lains, 2010). Such factors as work difficulty, low income, completely formal and inflexible style of leadership, 
work time, non- efficient communications and relations and many other factors can cause mental pressure in workers. If continue, can create mental and physical disorders (Faglum \& Valkom, 2005). Job stress in the work place may have detrimental effects on worker's mental and physical health. Stress is directly associated with cardio pathy, stroke and damages due to workplace incidences, additionally stress is causes of depression and anxiety (Teasdal, 2006). Then negative effect of pressure mental on organizational efficiently and is resulting in weak performance and leaving the job. Eventually, mental pressure leads to job exhaustion, a phenomenon in which person is extremely worn out and loses their strength and becomes indifferent toward co-workers. Their productivity and self-esteem are damaged extremely (Millward, 2005). Managers always say that they are too busy and have no sufficient time. While time is completely in their hands. What they do not possess actually is necessary skills for setting up their time (Mackenzie, 1993). By applying organizational skills of time management, various resources of time-based stress can be removed and then, stress and its negative effects fall down. Organizational skills in time management are those by which a manager fulfills deserving activities in effective use of time in order to realize organization aims and perform his/her job functions and duties (same). To attain this objective, experts have mentioned a variety of skills; Mackenzie (1993) considers the development of given goals as first step in time management. Jey (2007) suggests: goal setting is the main part of time management. Without having certain goals, you possibly gain many things which you do not need, and really they possess no benefits for organization. That is the same as time wasting. Time management is possible only when the goals have been defined clearly. Manager face with a lot of objectives and problems, sometimes the amount of work is so heavy that can be back breaking Manager, in order to sustain the heavy load of work in organization, should determine the priorities and allocate a given time for each. Murphy (1992) in his article-"trick of time" considers prioritization of goals and functions as necessary factors for proper management of time. Haynes (1987) says: "The essence of time management is that you have to utilize your best and the most energetic times in the most important works, so that you achieve a lot of desirable results". Regarding the importance of prioritization of works, Mackenzie (1993) underlines that key of success in time management is the fact that the most important works should be dealt with it before the rest of works. Main focus should be placed on those important works, while other less important works have to be avoided and put out of mind. Advantage or particularity of daily planning is identification of preferences. Only based on performance of activities and time of implementation, we can do works effectively and be assured that our time has been spent as efficiently and usefully as possible. First step of each work is to express the preferences. For being assured of meeting the aims and performing the works, some plans should be made. Planning guarantees the performance of preferred work. It also places the works under control. The concept of planning is focus of "time management". We need to allocate time, especially for planning purposes (Jey, 2007). Every organization is founded on planning. One of the main functions of manager is planning and foreseeing. Specially, when the resources, available to managers, are limited but their expectations are countless, the importance of planning becomes more tangible (Alwani, 2006). Also, Henry (2010) believes that a good plan-maker assigns an empty place in the processes of planning for changes, crises, and what 
has not been expected. It is obvious that a manager cannot solve all problems and do all works. Therefore, if you have to do a lot of work, but do not have enough time, you need not to do necessarily the tasks yourself, rather, you can entrust someone else to do your task. Foss (2005) says that: "Giving over the authority to others is one of the main skills of management. By entrusting authority properly, you can save your time, develop your employees and motivate them. The managers, who are aware of their subordinates' ability, can make reasonable decisions (that is, who should be assigned to what position). Though channel of communication with others in the organization, managers initiate to compile their plans and they also decide the best way of entrusting the authority. All managers' activities such as planning, organizing, power- entrusting are manifested through communications. Effective communication is one of the most necessary skills of time management. Muslims claim that one of the vital factors of time wasting is inability in establishing communication with others. On the other hand, Farner (2002) believes that among the factors of time wasting, meetings are the worst. Moreover, Mackenzie (1993) considers the meetings as one of the time wasting factors for managers and refers to aimlessness, insufficient or too many meetings, and inability in summing up the results and following them (as the main reasons of time-wasting).Therefore, ministry of education, as the foundation of other systems, needs to meet the mentioned aims with proper planning in the framework of time. As life- creating members of organization, managers are appointed and can be considered as good pattern and examples for other workers to follow. Valuing the time and managing is properly played a vital role in the whole system by managers. Organizational skills, applied in the research involve goal setting, aims and activities prioritization, operational planning, delegation of authority, management of communications and meetings. Therefore, with respect to the role of the management in increasing the level managers' success and effectiveness, the subject of time management and it's relation with occupational stress among managers of educational system are discussed, examined and studied in this research according to following two questions .

\subsection{Research Questions}

1. Q1- Is there a significant relationship between time management organizational skills and job stress?

2. Q2- Which of the subscales of time management organizational skills can better predict job stress?

\section{Theoretical framework of research}

By reviewing the conclusion of studies and researches done by the experts of time management, the skills of time management can be distinguished as two general terms of individual and organizational skills. Organizational skills of time management involve six dimensions: goal setting, prioritization, operational planning, delegation of authority, management of communications and management of meetings (Mackenzie, 1987), as shown in the figure (1-1), the more organizational skills of time management, the less organizational stress. Increased job stress implies poor organizational skills of time management. 


\section{Population and Sample}

Regarding the nature of the present research which seeks to examine the relation of organizational skills of time management with occupational stress, the research method is correlation. This research carried out in Zahedan city. It is center of Sistan and Baluchestan province that places in east south of Iran. Population of this research contains all managers (principals), assistants and responsible experts of general administration, districts 1 and 2, of Zahedan city in Iran. Since, the population is too small, trend of sample was not conducted and the whole population was considered. Population of current study involves 67 persons, that 5 person did not participtated in the research.

\section{Tools Used to collect the data}

Two questionnaires of time management and occupational stress were used.

\section{Organizational Skills of Time Management Questionnaire}

The research- made questionnaire was used to estimate the organizational skills of time management. This questionnaire contains 41 questions and each item is rated from always to never. Assigning: 1- means never, 2- means rarely, 3- means sometimes, 4- means often and 5- means always. The alpha reliability was reported $0 / 79$. This questionnaire includes six dimensions, namely: goal setting, prioritizing, operational planning, authority entrusting, management of communication and management of meetings.

\section{Job Stress Questionnaire}

This questionnaire was developed by Moghimi (2007) in order to assess the job stress of educational managers (principals). This questionnaire includes 20 items and each item is rated from always to never. Assigning: 1-means never, 2-means rarely, 3-means sometimes, 4-means often, 5-means always. The standardized alpha reliability was reported 0/83.

\section{Findings}

The results of table- 1 depicts that there is a significant negative correlation $(r=-0 / 31, p=0 / 014)$ between organizational management and job stress

As it is shown on table-2, the scores of management of meetings explained $0 / 14$ of the variance in job stress. In the second step management of meetings scores and operational planning scores together explained $0 / 23$ of the variance in job stress. The scores of management of meetings made the largest unique contribution (Beta $=-0 / 38, p=0 / 007)$ then it was a significant negative predictor for job stress. Also operational planning made a statistically significant contribution $(B e t a=-0 / 30, p=0 / 01)$ and it was a significant negative predictor for job stress

\section{Discussion and Conclusion}

The results of Pearson correlation revealed that there was a significant negative correlation between time management organizational skills and job stress. By increasing the level of time management organizational skills the amount of job stress decreases. The results of this research are in consistent with Hashemizade's research (2006). Hashemizade examined the relation between behaviors of time management and nurses' job stress and observed an 
inverse and significant relationship between time management behaviors and job stress. Same results were reported by Brigitte (2007). He concluded that time management behaviors positively was related to job satisfaction and negatively related to stress. It is also emphasized by Mackenzie's (1987) and Shaikh Nezami's (1998) that time management of managers decreases the mental pressures. Rahimi (2000) expresses that lack of time management is one of the most stressful factors. Since, one of the stress factors is time, issue of time and its management is very important. Locket (1994) considers the time as one of the stressful factor. In today working world time is valuable, due to this, time management courses should be implemented most often. Additionally, Frost (1992) suggests that time is a factors of pressure everywhere. There is a potential relation between this valuable factor and job stress. Therefore, the results of the present research are consistent with these viewpoints. Also, the results of this research are similar with the results of a research, carried out by Mohammadian (2006) who examined the relation between organizational and individual skills of time management and observed a positive and meaningful relation between organizational and individual skills of time management. Additionally, it can be inferred that knowledge of management science, especially time management has influenced the individuals very much. The results of stepwise regression showed that the scores of management of meetings had a significant negative relationship with job stress and it was a negative predictor for job stress, also operational stress and it was a negative predictor for job stress. As we earlier discussed, among time wasting factors, holding of meeting was the most important than others. Meetings are considered very important by people. Nowadays, no central building is without conference room. No organization, even middle sized, exists without managing board room (Mackkenzie, 1993). Witli (1995) says if managers evaluate the condition before attending every meetings, by being aware of existing state, they can prevent from mental pressure (Mackenzie, 1993) suggests that the main problem of these meetings is that they are not held on time. In this delay, not only the early minutes are lost, but also the audiences get tired during the whole meetings. According to Alavi (1994) management of meetings is an art and its' precondition is time management. The results are adopted with these opinions. In second step, operational planning has come to help the management of meetings and taken the rate of prediction to $0 / 23$. This variable has lonely been able to predict educational managers'job stress. The concept of planning is the central focus of time management. We need, especially to assign the time for the purpose of planning (Jey, 2007). Mackenzie (1993) has brought forth the subject of planning in the time as one of the main functions. He believes that one of the managers' time wasting factors is their false perception toward planning. « The reason, he says, is lack of managers' awareness from importance of planning. Each hour spent for effective planning, in practice becomes four- fold and results in better outcomes». Related to planning, Nakhjawani (2002) believes planning helps us in two aspects, so that we make our life orderly. Firstly, it tells us how to reach where we want to be. Secondly, it can identify needed resources to meet given objective. The results of this research were studied to clarify these insights

\section{References}

Akbaridizgah, H. (2009). Job Stress and its management. Gilan

Alahgeband,A. (2006). General management. Tehran Alwani, Mahdi. General management. 
Tehran

Alawi, A. (1993). Mental and nervous pressures in organization

Brigitte ,J., Rutte ,C. G., \& Roe ,R. A. (2007).A Review of the Time Management Literature. Personal Review, 36, 255-276

Chung,Y.L. (1989).Time Management Strategy,Job Satisfaction. Research Productivity, and Life Satisfaction of university Faculty. Dissertation Abstract International, 49(9), 2559.

Falkume, E., \& Vaglum,P. (2005). The Relationship between Interpersonal Problems and Occupational Stress in Physicians.General Hospital Psychiatry, 27, 285-291

Farner, J. (2004). Applied management of time.

Farner,J. (1998). Successful Time Management. New York, USA

Foss, J. N., \& Kend, L. (2005). Performance Pay, Delegation and Multitasking under Uncertainty and Innovativeness: An empirical Investigation. Journal of Economic Behavior \& Organization, 58(2), 246-276. http://dx.doi.org/10.1016/j.jebo.2004.03.018

Frost, P. (1994). Pressure relieving through time management.

Green,P., \& Skinner,D. (2005). Does Time Management Training Work: an Evaluation. International Journal of Training and Development, 9, 39-124.

Hashemizadeh, H. (2006). Examining the relation of organizational behavior of time management and job stress in nurses, surgery ward.

Haynes,M. E. (1987). Make Every Minute Count. Kogan Page.

Islami, S. (1994).Applicational management of time. Tabriz.

Jay, R. (2007). Time management, Principles, concepts and techniques.

Kendall,E. (2003). Measurement of Occupational Stress Among Australian Workers.

Lains, A. (2010). Local Directors of school Education in Greece: Their Role and Sources of Job Stress. Educational Management Administration \& Leadership, 38(4), 454-471. http://dx.doi.org/10.1177/1741143210368145

Luthans, F. (2002). Organizational Behavior. New York,McGraw Hill.

Mackenzie,R. A. (1978). Time Management: From Principle to Practice. Training and development Journal, 32(7), 5-34.

Mackenzie, R. A. (1993). The Time Trap.Word Executives Digest, 14(11), 24-27.

Mchenry,J. D. (2010). Time Management Aircraft maintenance Technology. Ft. Atkinson. 21(10), 3-64

Millward,L. (2005). Understanding Occupational and Organizational Behavior. London, Sage 
Moghimi, M. (2007). Organization and management a researching approach. Tehran.

Mohammadian, A. (2006). Study of time management skills.

Murphy,C. (1992). The Trick Of the Hour,Currents, 18(6), 50-54

Nakhjavini, S. (2000). How to use time properly? Mashayekhi, Mohammad. (2003). Capital, time, human.tadbir, 134,101

Nonise,S.A., Teng, J. K., \& Ford, C. W. (2005). A Cross Cultural Investigation of Time Management Practices and Job Outcomes. Int J Intercut Relate, 29, 409. http://dx.doi.org/10.1016/j.ijintrel.2005.05.002

Orlikowesky,W., \& Yates ,J. (2002). It's About Time: Temporal Structuring in Organizations. Organic, 13, 684-700

Rahimi, Sh. (2000). Time Management,77, 84-89

Robbins,S. P. (2009). Organizational Behavior. Prentice- Hall

Seiwert, L. (2005). Time management.

Sheikh Nezami, Z. (1998). Comparison of self-leading and its dimensions among girl high school principles. Shiraz

Teasdal,E. (2006). Workplace Stress,Post.Traumatic Disorders, 5, 251-255

Vitli, D. (1995). Victory psychological. Tehran

\section{Notes}

Table 1. Relation between organizational skills of time management and occupational stress

\begin{tabular}{|l|l|l|}
\hline variables & \multicolumn{2}{|l|}{ Pearson's correlation } \\
\hline Time management organizational skills & $\mathrm{r}$ & $\mathrm{sig}$ \\
\hline Occupational stress & $-0 / 31$ & $0 / 014$ \\
\hline
\end{tabular}

Table 2. Stepwise regression of time management organizational skills job stress

\begin{tabular}{|l|l|l|l|l|l|l|}
\hline steps & $\mathrm{R}$ & $\mathrm{R}^{2}$ adjust & Beta & $\mathrm{F}$ change & $\mathrm{t}$ & $\mathrm{sig}$ \\
\hline $\begin{array}{l}1- \\
\text { Management of meeting }\end{array}$ & $0 / 38$ & $0 / 14$ & $-0 / 38^{* *}$ & $10 / 39$ & $-2 / 80$ & $0 / 007$ \\
\hline $\begin{array}{l}\text { 2- } \\
\text { Management of meeting+ operational planning }\end{array}$ & $0 / 48$ & $0 / 23$ & $\begin{array}{l}-0 / 32 * * \\
-0 / 30 * *\end{array}$ & $6 / 78$ & $-2 / 60$ & $0 / 01$ \\
\hline
\end{tabular}




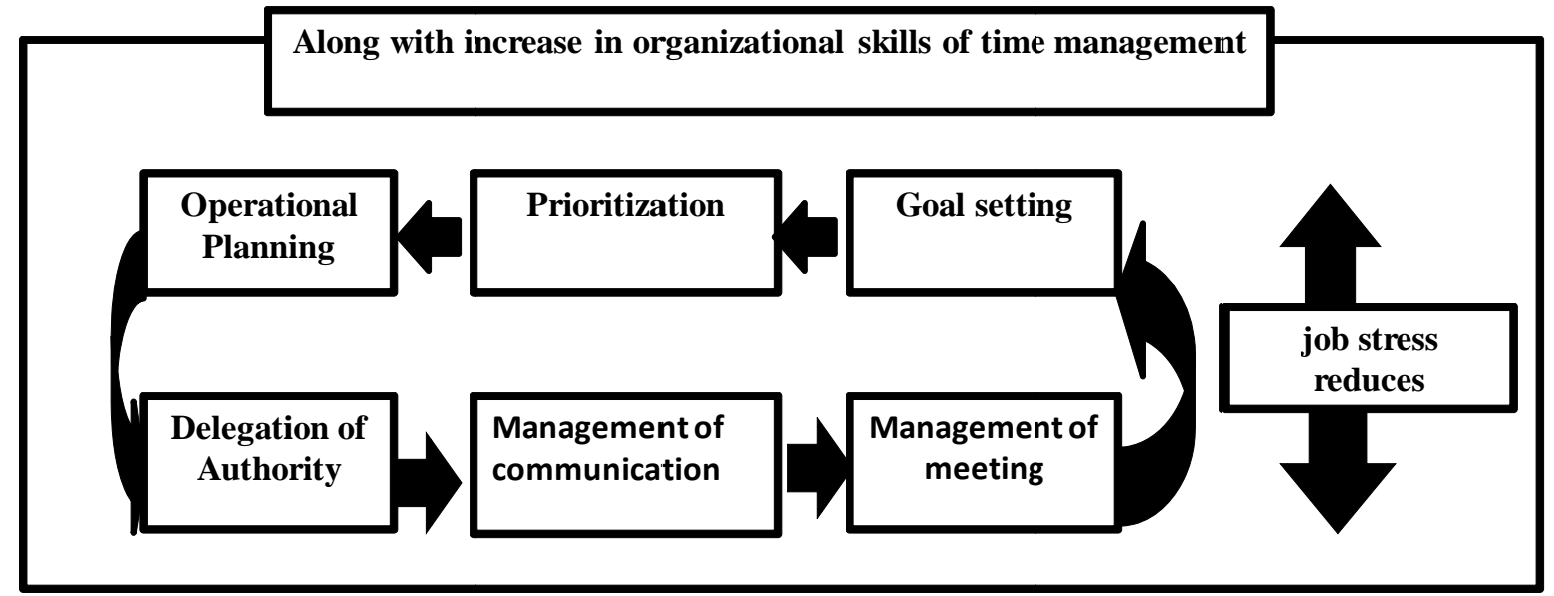

Figure 1-2. Relation of organizational skills of time management with occupational stress 